\title{
Conservação dos recursos hídricos em brejos de altitude - $O$ caso de Brejo dos Cavalos, Caruaru, PE
}

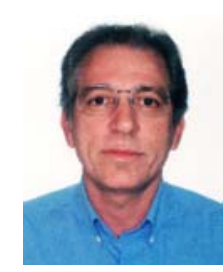

\author{
Ricardo A. P. Braga ${ }^{1}$, Jaime J.S.P. Cabral ${ }^{1}$, Suzana M.G.L. Montenegro ${ }^{1}$ \& Geraldo S. Perrier Júnior ${ }^{2}$ \\ 1 Grupo de Recursos Hídricos, Departamento de Engenharia Civil/UFPE, CEP 50740-530, Recife, PE. Fone: (81) $3271-8223$. \\ E-mail: rbraga@hotlink.com.br (Foto), jcabral@npd.ufpe.bre monte@hotlink.com.br \\ ${ }^{2}$ Bolsista do CNPq. E-mail: gperrier@ig.com.br
}

Protocolo $82-5 / 6 / 2001$

\begin{abstract}
Resumo: Brejos de altitude são formações vegetais disjuntas da Mata Atlântica, que ocorrem no Agreste de Pernambuco e Paraíba, como ilhas de umidade no ambiente semi-árido da Caatinga. 0 Parque Vasconcelos Sobrinho, situado na Serra dos Cavalos, em Caruaru, PE, é um exemplo do pouco que resta desses brejos na região. Com 359 ha, abriga uma floresta exuberante e diversos corpos d'água, porém vem sofrendo intenso processo de degradação, em decorrência da agricultura irrigada em seu interior e da exploração de argila no entorno. Para uma caracterização dos recursos hídricos foram obtidos, no período de 1998 a 2000, dados de chuva, de vazão nos riachos do Chuchu e Capoeirão, e de qualidade da água, nos dois cursos d'água e nos três maiores reservatórios existentes no Parque. No estudo de demandas pelo uso da água, ênfase maior foi dada aos conflitos da atividade de irrigação em relação ao uso da água para abastecimento público e à preservação dos ecossistemas locais. Neste trabalho, conclui-se que em Brejo dos Cavalos a precipitação pluviométrica é superior a do seu entorno, devido a razões orográficas e à própria existência da floresta remanescente, mas o desmatamento progressivo tende a alterar as condições microclimáticas locais. Neste contexto, o cultivo do chuchu é o principal consumidor de água no Parque, gerando perda de vazão dos cursos d'água e menor aporte para os reservatórios, os quais já começaram a sofrer assoreamento, devido a processos erosivos gerados sobretudo pelos desmontes na exploração da argila. Tais constatações exigem ação imediata do poder público, principalmente a implantação de um Plano de Manejo para o Parque.
\end{abstract}

Palavras-chave: relação floresta-água, usos da água, gestão ambiental, mata atlântica, áreas protegidas

\section{Conservation of water resources in humid areas in Northeastern Brazil. A case study of "Brejo dos Cavalos", Caruaru, PE}

\begin{abstract}
Humid areas at high altitude are found in semi-arid region of Pernambuco and Paraíba in Northeastern Brazil. Although the vegetation in the surrounding area is the semi-arid 'caatinga', in these high altitude areas, natural vegetation is similar to that of the Atlantic Forest. Municipal Ecological Park "Vasconcelos Sobrinho", is situated in "Brejo dos Cavalos" in Caruaru in the State of Pernambuco - Brazil and is a remnant example of this kind of environment. The park, with 359 ha, has a rich forest and several streamlets and dams. But there is a degradation process due to irrigated agriculture inside the park and due to clay exploitation in its borders. Water Resources in the ecological park have been studied from 1998 to 2000. Rainfall in "Brejo dos Cavalos" is significantly higher than in surrounding area because of the altitude and the forest itself. A slow but progressive process of deforestation jeopardizes local climatic conditions. Increasing irrigated crops, mainly chayote, reduces water volume in embankments. Erosion in both deforested area and clay exploitation area leads to soil impoverishment and silting up of dams. An urgent action from municipal government is needed to stop degradation and set up of an environmental management program.
\end{abstract}

Key words: forest-water relation, water uses, environmental management, atlantic forest, protected areas 


\section{INTRODUÇÃO}

Os brejos de altitude são formações vegetais úmidas e subúmidas, inseridas na região da Caatinga de Pernambuco e Paraíba, onde predomina uma vegetação xerófila, típica de ambientes semi-áridos (Lima, 1960). Essas ilhas de vegetação arbórea mais densa são condicionadas pela orografia, proporcionando um microclima diferenciado, com pluviosidade bem superior à do entorno (Andrade \& Lins, 1964).

A floresta típica dos brejos de altitude guarda forte semelhança com a floresta úmida litorânea, ocorrendo espécies vegetais e animais comuns a ambos os ecossistemas; por isso, são consideradas formações disjuntas de Mata Atlântica (Rodal, 1998).

As condições de fertilidade e de disponibilidade hídrica atraem agricultores para implantar lavouras, predominantemente de ciclo curto, como as hortaliças. Tal fato exerce forte pressão predatória sobre a floresta e a água (Vasconcelos Sobrinho, 1971).

A maioria dos brejos de altitude localiza-se no Maciço da Borborema, que exerce em Pernambuco e Paraíba importante papel no conjunto do relevo, na diversificação do clima e nas principais redes de drenagem. Assim, grande parte dos rios litorâneos dos dois estados origina-se e possui grandes afluentes nesta região do agreste (SUDEMA, 1992; SECTMA, 1998). Dentre eles, destacam-se os rios Una, Ipojuca e Capibaribe, em Pernambuco, e os rios Paraíba, Miriri, Maranguape e Curimataú, na Paraíba.
O Brejo dos Cavalos constitui um dos mais significativos remanescentes de Mata Atlântica, situando-se no município de Caruaru, PE, onde se localiza o Parque Ecológico João de Vasconcelos Sobrinho, criado pela Lei Municipal $n^{\circ}$. 2796, de 07 de junho de 1983. Com 359 ha, o parque abriga uma floresta exuberante e de significativa diversidade, além de conservar, em seu interior, mananciais hídricos para abastecimento público (CPRH, 1994). A área foi considerada como de prioridade máxima para conservação no 'Workshop' sobre Áreas Prioritárias para a Conservação da Mata Atlântica do Nordeste (Conservation International, 1993).

Apesar de sua condição de Unidade de Conservação, o Parque vem sofrendo, ao longo dos anos, grande pressão antrópica, caracterizada, sobretudo pela substituição gradativa da Mata, através da expansão da agricultura, pela exploração de argila com desmonte de morros periféricos, pela presença de moradores no seu interior e, sobretudo, pelo excessivo consumo de água na atividade de irrigação (Braga, 1999).

Visando investigar os recursos hídricos nos brejos de altitude, particularmente em Brejo dos Cavalos, pesquisadores do Grupo de Recursos Hídricos da UFPE participaram do Projeto "Recuperação e Manejo de Brejos de Altitude de Pernambuco e Paraíba", apoiado pelo Programa de Conservação e Utilização Sustentável da Biodiversidade Biológica Brasileira (PROBIO) que tem o patrocínio do Banco Mundial (GEF-BIRD) através do Ministério do Meio Ambiente.

O subprojeto de recursos hídricos no Parque Vasconcelos Sobrinho tem por objetivos: caracterizar e quantificar as águas superficiais, avaliar o seu uso e analisar a relação entre floresta e água, além de contribuir para a elaboração e implantação do

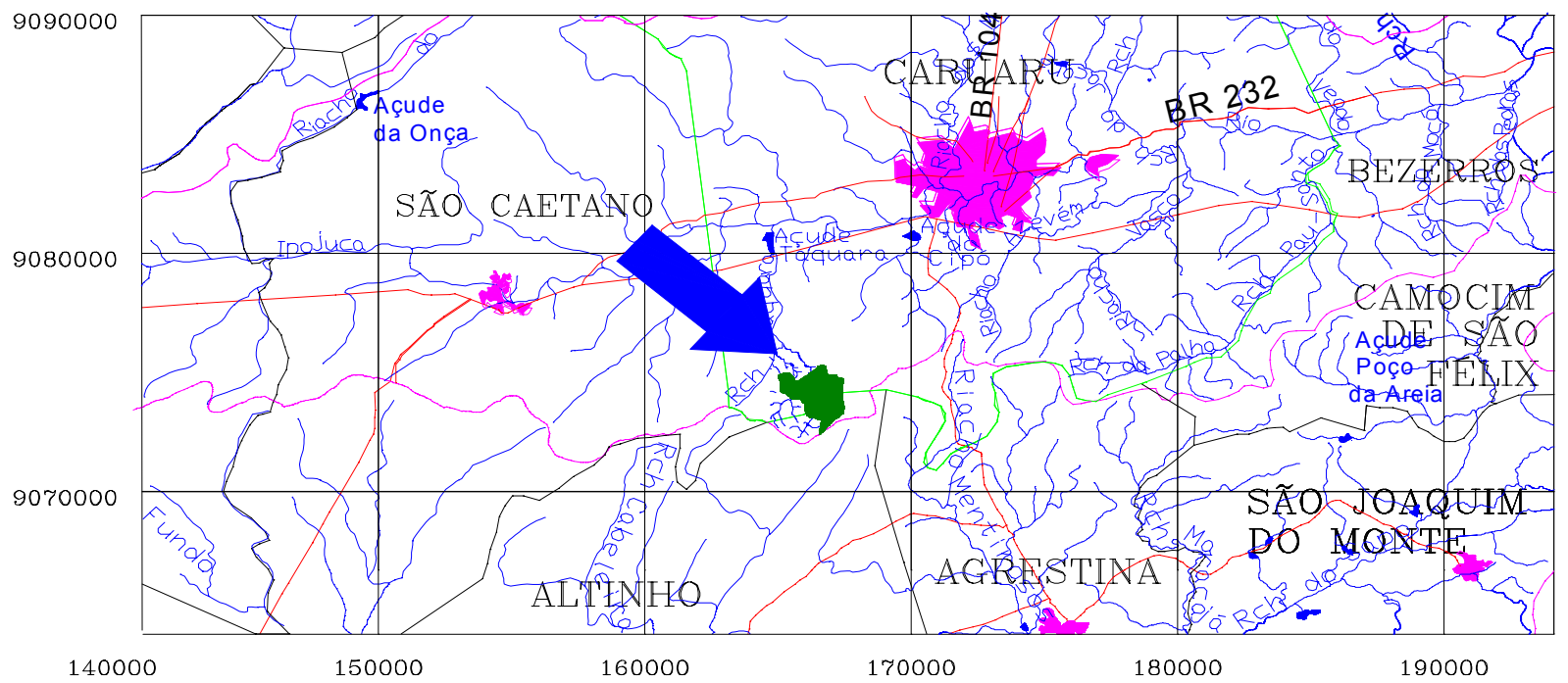

$\mathbb{L} \mathbb{E} G N \mathbb{D} A \quad \mathbb{B} A S I C A$

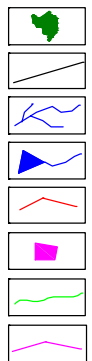

Parque Ecológico Vasconcelos Sobrinho

Limite municipal

Rede hidrográfica

Açúdes

Rede viária

Sedes municipais

Limites de Caruaru

Limites das bacias

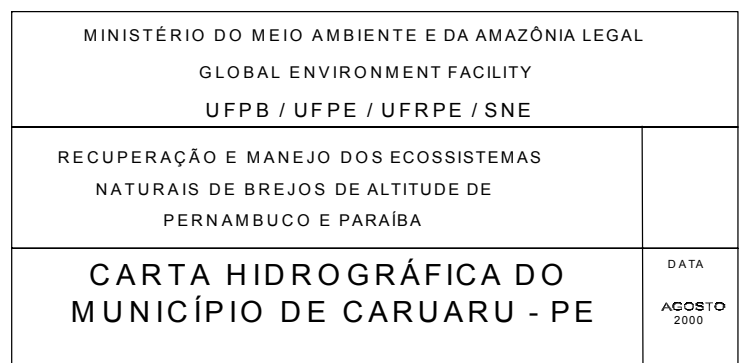

Figura 1. Localização do Parque Ecológico Vasconcelos Sobrinho, Caruaru, PE 
Plano de Manejo do Parque. O presente trabalho apresenta uma síntese dos resultados desse subprojeto.

\section{MATERIAL E MÉTODOS}

\section{Hidrografia e hidrogeologia}

A localização do Parque Ecológico Vasconcelos Sobrinho é apresentada na Figura 1. Devido à sua topografia acidentada, com curvas de nível que variam de 800 a 950 m, ocorre uma drenagem razoavelmente bem definida, com dois cursos d'água principais: os riachos do Chuchu e Capoeirão. Ambos nascem fora dos limites da Reserva, sendo constituintes da sub-bacia do rio Taquara, afluente da margem direita do rio Ipojuca. Esta sub-bacia possui uma área de drenagem de 2.101 ha, ultrapassando, inclusive, os limites do município de Caruaru, expandindo-se até Altinho (Fig. 2).
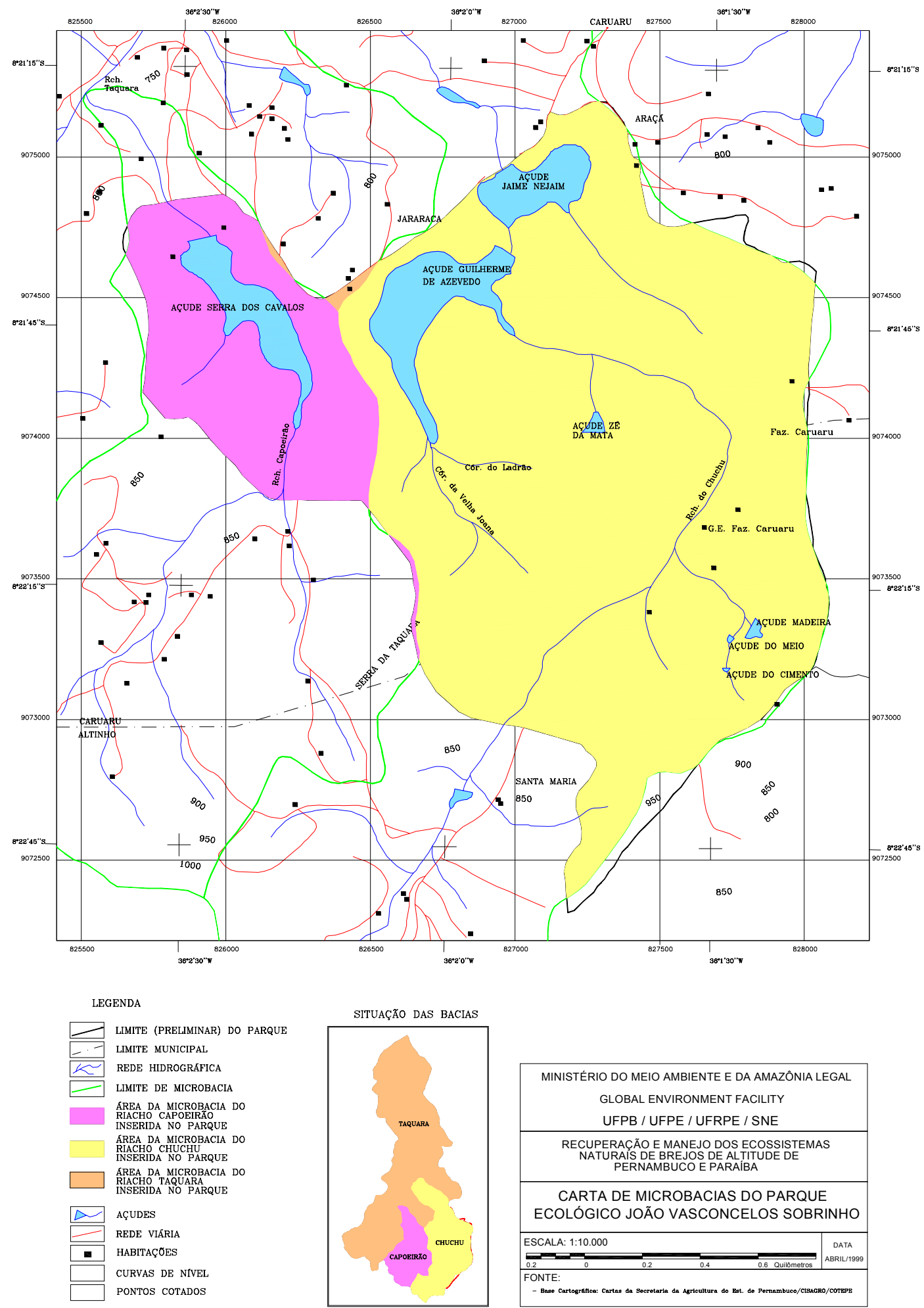

Figura 2. Carta de microbacias do Parque Vasconcelos Sobrinho, Caruaru, PE 
$\mathrm{O}$ riacho do Chuchu, que possui $5.755 \mathrm{~m}$ de extensão, apresenta $2.900 \mathrm{~m}$ (cerca de 50\%) no interior da Unidade de Conservação; já o riacho Capoeirão apresenta $1.265 \mathrm{~m}$ no interior do Parque, correspondendo a $45 \%$ da sua extensão total. Ambos são cursos d'água rasos, estreitos e poucos declivosos, com pequena capacidade de vazão, apresentando largura e profundidade média inferior a 1,5 e 0,6 m, respectivamente.

No interior do Parque existem três grandes açudes que servem como reserva estratégica para o sistema de abastecimento público da região; são os açudes Serra dos Cavalos, Guilherme de Azevedo e Jaime Nejaim que, juntos, somam $262.700 \mathrm{~m}^{2}$ de espelho d'água, correspondendo a cerca de 7,3\% da área total do parque, podendo acumular aproximadamente $2 \times 10^{6} \mathrm{~m}^{3}$ de água.

Afora os grandes reservatórios, existem mais quatro de pequeno tamanho, que somam $5.090 \mathrm{~m}^{2}$ de área inundável e capacidade total de acumulação estimada em cerca de $5.240 \mathrm{~m}^{3}$; são os açudes do Cimento, do Meio e Madeira, na margem direita do Riacho do Chuchu, e o açude Zé da Mata, na margem esquerda. A Tabela 1 apresenta os dados de área e o volume dos açudes do Parque.

Tabela 1. Resumo das características métricas dos açudes existentes no Parque Vasconcelos Sobrinho (Caruaru, PE)

\begin{tabular}{lcc}
\multicolumn{1}{c}{ Açude } & Superfície $\left(\mathrm{m}^{2}\right)$ & Volume $\left(\mathrm{m}^{3}\right)$ \\
\hline Guilherme de Azevedo & 118.528 & 786.000 \\
Serra dos Cavalos & 81.101 & 761.000 \\
Jaime Nejaim & 63.073 & 400.000 \\
Madeira & 2.390 & 5.500 \\
Zé da Mata & 2.140 & 2.200 \\
Meio & 339 & 310 \\
Cimento & 245 & 407 \\
\hline
\end{tabular}

Como formadoras dos cursos d'água, são encontradas algumas nascentes no interior do Parque. Durante o período chuvoso podem ser encontrados vários pontos de ressurgência, formadores de pequenos cursos d'água, que convergem para os riachos ou diretamente para os açudes.

A região do Parque localiza-se sobre a camada geológica do embasamento cristalino, com pequena espessura de solos formados por processos de intemperismo. Em alguns trechos, o embasamento rochoso chega a aflorar, porém em outros mais baixos a camada de aluvião atinge alguns metros de espessura. Nesses trechos de cota mais baixa, a camada de sedimentos de origem aluvionar, apresenta boa capacidade de armazenamento de água.

\section{Monitoramento}

No período de agosto de 1997 a julho de 2000, foram realizadas visitas mensais à Serra dos Cavalos, onde se localiza o Parque Municipal Vasconcelos Sobrinho. O trabalho de investigação consistiu, inicialmente, de observações de campo, registro fotográfico e entrevistas com moradores locais e usuários da água. Em seguida, foram definidas estações de coleta de dados de chuva, vazão e qualidade da água, visando caracterizar os recursos hídricos da área. Como apoio, foram utilizadas cartas altimétrica, hidrográfica e de uso do solo (escala 1:25.000) geradas pelo mesmo projeto onde se insere esta pesquisa.
Para avaliação da pluviosidade foram instalados dois pluviômetros, próximos à casa de apoio aos pesquisadores, no interior do Parque. Um dos pluviômetros é do tipo convencional, com leitura diária efetuada por um observador, e o outro é automático, com registro digital dos dados em “datalogger". As informações obtidas desde agosto de 1998 permitiram fazer-se correlações necessárias à avaliação do aporte de águas nessas áreas.

Para estimativa de vazão nos riachos Chuchu e Capoeirão, foi utilizado um micromolinete com medições mensais desde 1997. Em maio de 1999, foi construída uma calha tipo Parshall no leito do riacho do Chuchu, o que permitiu a medição diária da sua vazão.

Foram escolhidos pontos de amostragem para avaliação da qualidade da água nos cursos d'água existentes no Parque Vasconcelos Sobrinho: o riacho do Chuchu e o riacho Capoeirão. Simultaneamente, foram realizadas amostragens nos açudes Serra dos Cavalos, Guilherme de Azevedo, Jaime Nejaim e Madeira. Os parâmetros de qualidade da água analisados foram $\mathrm{pH}$, condutividade elétrica, cloretos, sólidos totais, oxigênio dissolvido e nitrogênio total, seguindo-se as orientações do Standard Methods for the Examination of Water and Wastewater (APHA, 1995) e do Guia de Coleta e de Preservação de Amostras de Água (CETESB, 1988).

Em decorrência de mineração de argila situada na entrada do Parque, foram também realizadas medidas de sedimentação de material erodido, através da instalação de um tanque de sedimentos, à jusante da área em processo erosivo, permitindo quantificar-se os sedimentos carreados para o leito do Açude Jaime Nejaim.

\section{RESULTADOS E DISCUSSÃO}

\section{Pluviometria e fluviometria}

Os dados pluviométricos coletados em Brejo dos Cavalos são apresentados na Figura 3, sob a forma do total de precipitações mensais, no período de setembro de 1998 a agosto de 2000 . Observa-se que no primeiro ciclo de 12 meses a pluviosidade foi mais baixa, em decorrência do efeito do "El Niño", atingindo apenas 1.141,9 mm; no entanto, nos 12 meses seguintes a pluviosidade atingiu $1.957,6 \mathrm{~mm}$, com um incremento de $71,43 \%$ no total. Em todo o período de 2 anos, o maior valor de precipitação diária foi de $84,0 \mathrm{~mm}$, ocorrido no dia 12 de fevereiro de 1999, no intervalo de apenas $1 \mathrm{~h} 15 \mathrm{~min}$.

Os dados obtidos em 1999 indicam precipitação anual de 1.396,9 mm. Comparada com os dados das estações localizadas em outras áreas do Brejo Pernambucano, como o Brejo da Madre de Deus $\left(805,7 \mathrm{~mm}^{2} \mathrm{ano}^{-1}\right)$ e a Barra de Guabiraba

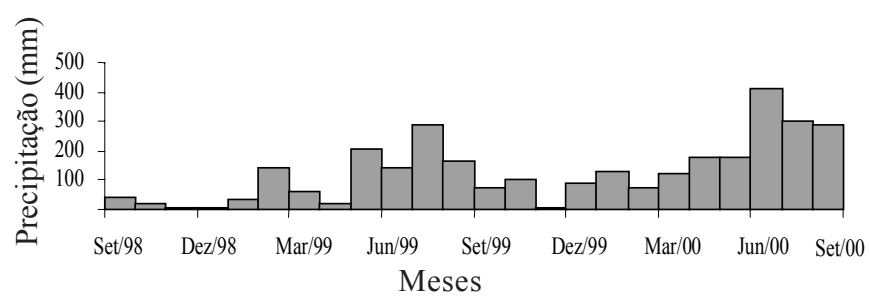

Figura 3. Precipitações mensais registradas no período de setembro de 1998 a agosto de 2000, na estação Brejo dos Cavalos 
$\left(1.125,5 \mathrm{~mm} \mathrm{ano}^{-1}\right)$, ela é superior em 66 e $19 \%$, respectivamente. Por outro lado, comparando-se a precipitação de Brejo dos Cavalos com a área do entorno, como na cidade de Caruaru (335,3 mm) e no município vizinho de Altinho, verifica-se que esta diferença é ainda maior, indicando em 300 e $177 \%$ a mais, respectivamente (Fig. 4). Tal fato decorre de razões orográficas e da manutenção da própria floresta remanescente de Mata Atlântica.

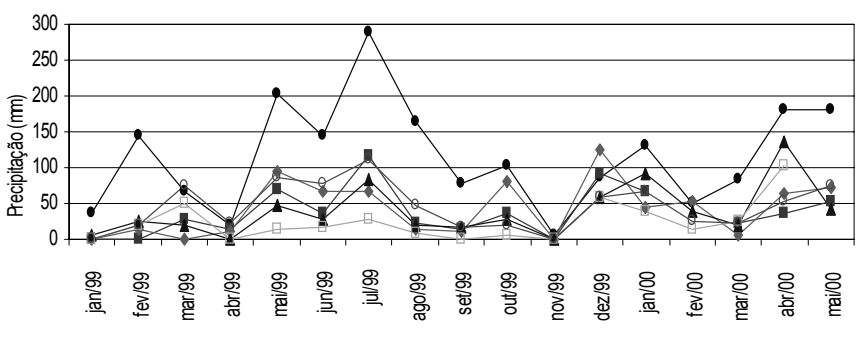

$\rightarrow$ Serra dos Cavalos $\rightarrow$ - Agrestina $\rightarrow-$ Altinho $\rightarrow$ - Caruaru I - - São Caetano I - o São Joaquim do Monte Figura 4. Precipitações pluviométricas em estações próximas a Brejo dos Cavalos, no Agreste Pernambucano

Durante o verão 1998/99, a vazão nos principais cursos d'água do interior do parque foi totalmente nula, em conseqüência do longo período de estiagem observado naquela época, bem como pela prática de irrigação na região, que aumentou de forma considerável. No segundo semestre de 1998 verificou-se a existência de mais de 50 bombas hidráulicas instaladas nos cursos d'água no interior e nos arredores do Parque, reduzindo consideravelmente os volumes d'água que chegam aos açudes principais.

A Figura 5 mostra as vazões medidas no riacho do Chuchu, no período de 1997 a 2000. Observa-se que o riacho chegou a secar no verão 1998/99 e 1999/2000, o que não acontecia há algumas décadas. Observando-se, também, que nas chuvas intensas a resposta da microbacia é rápida e atinge vazões consideráveis, como em agosto de 2000.

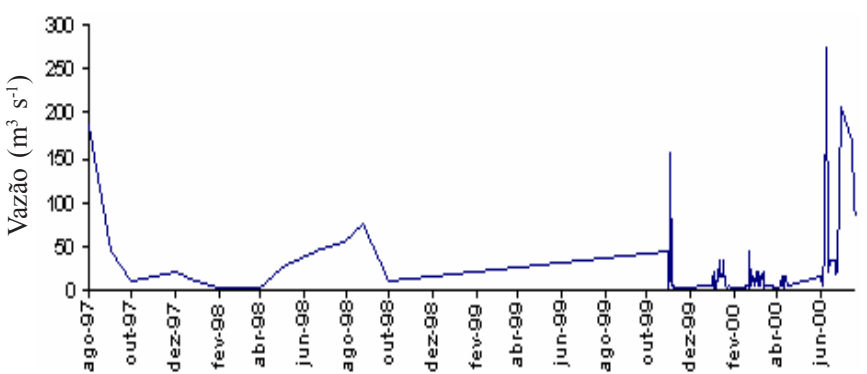

Figura 5. Vazões medidas no Riacho do Chuchu, no interior do Parque Vasconcelos Sobrinho, Caruaru, PE

\section{Qualidade da água}

A Tabela 2 apresenta o padrão de qualidade da água nos ambientes lóticos (riachos Capoeirão e Chuchu) e lênticos (açudes Serra dos Cavalos, Guilherme de Azevedo e Jaime Nejaim). Os dados de $\mathrm{pH}$, condutividade elétrica, cloretos, sólidos totais, oxigênio dissolvido e nitrogênio total, são apresentados por faixa de ocorrência de seus valores.

A partir dos dados obtidos, observa-se que a água é de boa qualidade para atender aos dois consumos preponderantes:
Tabela 2. Síntese dos dados de qualidade das águas superficiais no Parque Vasconcelos Sobrinho, Caruaru, PE

\begin{tabular}{|c|c|c|}
\hline \multirow[b]{2}{*}{ Parâmetro } & Cursos d'Água & Açudes \\
\hline & $\begin{array}{l}\text { Riachos Capoeirão } \\
\text { e do Chuchu }\end{array}$ & $\begin{array}{c}\text { S.C., } \\
\text { G.A., J.N.* }\end{array}$ \\
\hline $\mathrm{pH}$ & 6,5 a 7,8 & 6,3 a 7,4 \\
\hline $\begin{array}{l}\text { Condutividade Elétrica } \\
\left(\mu \mathrm{S} \mathrm{cm}^{-1}\right)\end{array}$ & 8 a 210 & 9 a 89 \\
\hline Cloretos $\left(\mathrm{mg} \mathrm{L}^{-1}\right)$ & 9 a 63 & 6 a 73 \\
\hline Sólidos Totais $\left(\mathrm{mg} \mathrm{L}^{-1}\right)$ & 96 a 197 & 91 a 290 \\
\hline $\begin{array}{l}\text { Oxigênio Dissolvido } \\
\left(\mathrm{mg} \mathrm{O}_{2} \mathrm{~L}^{-1}\right)\end{array}$ & 6 a 7 & 6 a 7 \\
\hline Nitrogênio Total & 0,3 a 1,9 & 0,6 a 2,5 \\
\hline
\end{tabular}

abastecimento público e irrigação. Saliente-se que o parâmetro coliformes fecais não foi mensurado, porque não existe qualquer indício de despejo de efluentes domésticos nos corpos d'água locais.

Dentro do Parque existe uma captação de água mineral (Fonte Vitalino) produzindo diariamente 1.600 recipientes de água com capacidade de 19,6 L. A fonte é cadastrada no Departamento Nacional de Pesquisas Minerais (DNPM). Suas características físico-químicas são apresentados na Tabela 3.

Tabela 3. Características físico-químicas da água mineral captada no Parque Vasconcelos Sobrinho, Caruaru, PE*

\begin{tabular}{|c|c|}
\hline Determinações & Resultados \\
\hline Turbidez & $0,1 \mathrm{uT}$ \\
\hline Cor & $<5,0 \mathrm{uH}$ \\
\hline $\mathrm{pH}$ & 5,7 \\
\hline Condutância específica à $25^{\circ} \mathrm{C}$ & $57,6 \mu \mathrm{S} / \mathrm{cm}$ \\
\hline Nitratos $(\mathrm{em} \mathrm{N})$ & $1,30 \mathrm{mg} \mathrm{L}^{-1}$ \\
\hline Oxigênio dissolvido $\left(\mathrm{em} \mathrm{O}_{2}\right)$ & $6,7 \mathrm{mg} \mathrm{L}^{-1}$ \\
\hline Sulfeto de hidrogênio & Ausência \\
\hline Dióxido de carbono livre $\left(\mathrm{em} \mathrm{CO}_{2}\right)$ & $48,6 \mathrm{mg} \mathrm{L}^{-1}$ \\
\hline Alcalinidade de hidróxidos $\left(\mathrm{em} \mathrm{CaCO}_{3}\right)$ & $0,0 \mathrm{mg} \mathrm{L}^{-1}$ \\
\hline Alcalinidade de carbonatos $\left(\mathrm{em} \mathrm{CaCO}_{3}\right)$ & $0,0 \mathrm{mg} \mathrm{L}^{-1}$ \\
\hline Alcalinidade de bicarbonatos $\left(\mathrm{em} \mathrm{CaCO}_{3}\right)$ & $10,0 \mathrm{mg} \mathrm{L}^{-1}$ \\
\hline Dureza total $\left(\mathrm{em} \mathrm{CaCo}_{3}\right)$ & $8,8 \mathrm{mg} \mathrm{L}^{-1}$ \\
\hline Dureza de carbonatos $\left(\mathrm{em} \mathrm{CaCO}_{3}\right)$ & $8,8 \mathrm{mg} \mathrm{L}^{-1}$ \\
\hline Dureza de não carbonatos $\left(\mathrm{em} \mathrm{CaCO}_{3}\right)$ & $0,0 \mathrm{mg} \mathrm{L}^{-1}$ \\
\hline Cloretos $(\mathrm{em} \mathrm{Cl})$ & $11,6 \mathrm{mg} \mathrm{L}^{-1}$ \\
\hline Sulfatos $(\mathrm{em} \mathrm{SO} 4)$ & $4,3 \mathrm{mg} \mathrm{L}^{-1}$ \\
\hline Sílica $\left(\mathrm{em} \mathrm{SiO}_{2}\right)$ & $9,2 \mathrm{mg} \mathrm{L}^{-1}$ \\
\hline Manganês (em Mn) & $0,010 \mathrm{mg} \mathrm{L}^{-1}$ \\
\hline Magnésio (em Mg) & $1,30 \mathrm{mg} \mathrm{L}^{-1}$ \\
\hline Alumínio (em Al) & $0,07 \mathrm{mg} \mathrm{L}^{-1}$ \\
\hline Cálcio (em Ca) & $1,39 \mathrm{mg} \mathrm{L}^{-1}$ \\
\hline Bário (em Ba) & $0,03 \mathrm{mg} \mathrm{L}^{-1}$ \\
\hline Potássio (em K) & $1,9 \mathrm{mg} \mathrm{L}^{-1}$ \\
\hline Sódio (em Na) & $7,8 \mathrm{mg} \mathrm{L}^{-1}$ \\
\hline
\end{tabular}

A captação vem sendo realizada através de poço tubular com 9,0 m de profundidade, enquanto outro poço, com profundidade de $12,0 \mathrm{~m}$, distante $15,0 \mathrm{~m}$ do primeiro, com vazão de $1.000 \mathrm{~L} \mathrm{~h}^{-1}$, é utilizado para lavagem dos botijões. Em épocas normais, a profundidade do nível estático é de $1,0 \mathrm{~m}$, porém no verão 98/99, o nível estático ficou reduzido a uma profundidade de $6,0 \mathrm{~m}$. 


\section{Assoreamento}

A extração de argila, situada à montante do Açude Jaime Nejaim, tem gerado forte processo erosivo, em conseqüência da retirada da cobertura vegetal e da movimentação de terras. Dados primários mostram que, durante chuvas fortes, porções das camadas superficial e subsuperficial do solo são transportadas diretamente para o açude, levando a um intenso assoreamento.

Em campanhas de medição, realizadas em julho e agosto de 2000, verificou-se que o material erodido trazido por enxurrada, acumulou-se em mais de $40 \mathrm{~cm}$ no tanque de sedimentação, de 2,00 m de comprimento e 1,00 m de largura, ali implantado.

A continuar o processo de desmatamento e de retirada indiscriminada de argila através de desmontes, inclusive com uso de máquinas, os processos erosivos poderão levar a um rápido assoreamento nos reservatórios, como já se evidencia no açude Jaime Nejaim.

\section{Uso da água no Parque}

No Parque Vasconcelos Sobrinho existem dois usos preponderantes da água: a irrigação e o abastecimento público de áreas urbanas, ambos considerados usos consuntivos, evidenciando-se conflito entre as suas finalidades, uma vez que a água terá que ser utilizada excludentemente para uma ou para a outra atividade. Uma outra demanda, porém de menor intensidade, é para atendimento individual dos moradores (geralmente através de poços rasos).

\section{Demanda para irrigação}

A atividade de irrigação se dá principalmente nos vales, em terras de várzea e margeando os cursos d'água. Embora contraditório com o que se preconiza em uma Unidade de Conservação, o cultivo de produtos agrícolas ocupa uma área de cerca de 81 ha, em vários lotes distribuídos ao longo dos principais vales. Esses lotes, que eram trabalhados apenas por moradores do interior do Parque ou da vizinhança, atualmente vêm sendo gradativamente ampliados, como conseqüência da venda indiscriminada da posse dos mesmos, em decorrência da procura por áreas com disponibilidade de água para irrigação.

O cultivo mais extenso e que simultaneamente mais demanda água, sobretudo na fase de crescimento da cultivar, é o de chuchu, ao qual se seguem os cultivos irrigados de outras hortaliças (alface, coentro, cebolinha, pimentão, cenoura e beterraba) e flores, sobretudo a celsa. $\mathrm{O}$ aumento do cultivo de olerícolas acarreta um duplo incremento nas agressões ambientais do parque, em função da necessidade de uso de agrotóxicos e do aumento da demanda de água para irrigação nesse tipo de cultura. Enfim, a cultura do chuchu (Sechium edule) é a maior consumidora de água no interior do Parque Vasconcelos Sobrinho. A partir das observações e quantificações em campo e de entrevistas com agricultores, tem-se os resultados a seguir.

A prática de irrigar individualmente cada planta de chuchu com mangueira durante a estiagem exige um trabalho que utiliza de 2,5 a 5,0 h d ${ }^{-1}$. Informação dos entrevistados e checagem com medição de tempo, indicam que, normalmente, cada planta é irrigada durante $2 \mathrm{~min} \mathrm{~d}^{-1}$ (podendo chegar a $4 \mathrm{~min}$, se esta prática não for diária). Desta forma, uma pessoa dispendendo uma média de quatro horas, é capaz de irrigar cerca de 120 plantas, o que equivale à cobertura de aproximadamente
0,43 ha de cultivo de chuchu, considerando-se a estimativa de 280 plantas ha-1.

As bombas hidráulicas, com potência que varia de 0,5 a 3 $\mathrm{CV}$, são instaladas no período de estiagem para captação de água diretamente do riacho ou de cacimbas (poços escavados manualmente e revestidos por alvenaria ou superposição de anéis de concreto pré-moldado), que medem cerca de 1,5 m de diâmetro e 3,0 m de profundidade, apresentando nível estático, que se situa a aproximadamente 1,0 $\mathrm{m}$ abaixo do nível do solo. Devido à grande estiagem verificada nos anos de 1998/99, foram escavadas diversas novas cacimbas, várias delas com anéis de concreto pré-moldado.

Esses poços escavados no leito dos riachos ou nas partes mais baixas da várzea recebem contribuição de águas superficiais drenadas ou do lençol freático, que é muito raso nesses pontos. Após o bombeamento completo, o nível d'água é restaurado gradativamente pela percolação da água subterrânea, levando entre 10 e $20 \mathrm{~h}$ para atingir os níveis iniciais.

Considerando-se o tipo de bomba, sua potência e o tempo de uso de $4 \mathrm{~h} \mathrm{~d}^{-1}$, a vazão de irrigação teve o valor estimado em $19,2 \mathrm{~m}^{3} \mathrm{~d}^{-1}$, em 0,43 ha. Ainda de acordo com este raciocínio, 1 ha de cultivo de chuchu consome, localmente, cerca de 44,6 $\mathrm{m}^{3}$ de água por dia, por meio de irrigação, utilizando-se de mangueira. Esse consumo corresponde a uma lâmina de $66,9 \mathrm{~mm}$ no período de $15 \mathrm{~d}$, cuja estimativa é inferior aos valores sugeridos por Oliveira et al. (1980), que indicam uma lâmina média de irrigação de $7 \mathrm{~mm} \mathrm{~d}^{-1}$, ou seja, $70 \mathrm{~m}^{3} \mathrm{ha}^{-1} \mathrm{~d}^{-1}$, para o cultivo do chuchu.

Tomando-se como base o levantamento cartográfico de uso do solo realizado pelo Projeto e fornecidos pelo Grupo de Educação Ambiental, do mesmo projeto, pode-se estimar que existem pelo menos 25 ha em área cultivada com chuchu no Parque, em 21 lotes dos 61 existentes. Considerando-se, ainda, o valor de 44,6 $\mathrm{m}^{3} \mathrm{ha}^{-1}$, estima-se o consumo de $1.115 \mathrm{~m}^{3} \mathrm{de}$ água diário, durante todos os dias dos sete meses de estiagem.

\section{Demanda para abastecimento público}

A carência de água para abastecimento aumentou sensivelmente nos últimos anos, em virtude da longa estiagem no verão 1998/99, que reduziu bastante os volumes armazenados nas barragens existentes na região. A população do Município de Caruaru, que apresenta uma necessidade de vazão de $800 \mathrm{~L} \mathrm{~s}^{-1}$, foi forçada a conviver com um forte racionamento de água. Nesse período, a Companhia Pernambucana de Saneamento - COMPESA, utilizou a reserva técnica das águas dos açudes Serra dos Cavalos, Guilherme de Azevedo e Jaime Nejaim, além de outros em diferentes sub-bacias, para reforçar a disponibilidade de água para o município. Como conseqüência dessa escassez, a água passou a ser "preciosidade", adquirindo maior valor comercial. A mineradora de água mineral que opera na área, ampliou a sua produção diária e pequenos comerciantes passaram a explorar água do interior do Parque, para comercialização no município de Caruaru. Ressalta-se que esses fatos evidenciam a importância estratégica da preservação dos mananciais existentes no Parque, o que torna imperativa a elaboração de um Plano de Manejo, para garantir o uso e a preservação do mesmo. 
Tabela 4. Estimativa de demandas hídricas (máxima e mínima) em mm, de diferentes culturas, para um período de quinze dias, tomando-se como base a climatologia do município de Caruaru, PE

\begin{tabular}{|c|c|c|c|c|c|c|c|c|}
\hline \multirow{2}{*}{ Cultura } & \multirow{2}{*}{ Nível } & \multicolumn{7}{|c|}{ Demanda Hídrica - mm } \\
\hline & & Agosto & Setembro & Outubro & Novembro & Dezembro & Janeiro & Fevereiro \\
\hline \multirow[t]{2}{*}{ Batata } & Máx. & 94,5 & 119,7 & 144,9 & 160,7 & 167,0 & 157,7 & 157,7 \\
\hline & Mín. & 36,0 & 45,6 & 55,2 & 61,2 & 63,6 & 60,0 & 60,0 \\
\hline \multirow[t]{2}{*}{ Beterraba } & Máx. & 108,0 & 136,8 & 165,6 & 183,6 & 190,8 & 180,0 & 180,0 \\
\hline & Mín. & 36,0 & 45,6 & 55,2 & 61,2 & 63,6 & 60,0 & 60,0 \\
\hline \multirow[t]{2}{*}{ Feijão } & Máx. & 94,5 & 119,7 & 144,9 & 160,7 & 167,0 & 157,5 & 157,5 \\
\hline & Mín. & 27,0 & 34,2 & 41,4 & 45,9 & 47,7 & 45,0 & 45,0 \\
\hline \multirow[t]{2}{*}{ Cana-de-Açúcar } & Máx. & 117,0 & 148,2 & 179,4 & 198,8 & 206,7 & 195,0 & 195,0 \\
\hline & Mín. & 36,0 & 45,6 & 55,2 & 61,2 & 63,6 & 60,0 & 60,0 \\
\hline \multirow[t]{2}{*}{ Banana } & Máx. & 81,0 & 102,6 & 124,2 & 137,7 & 143,1 & 135,0 & 135,0 \\
\hline & Mín. & 36,0 & 45,6 & 55,2 & 61,2 & 63,6 & 60,0 & 60,0 \\
\hline \multirow[t]{2}{*}{ Milho } & Máx. & 108,0 & 136,8 & 165,6 & 183,6 & 190,8 & 180,0 & 180,0 \\
\hline & Mín. & 36,0 & 45,6 & 55,2 & 61,2 & 63,6 & 60,0 & 60,0 \\
\hline
\end{tabular}

\section{Conflitos de uso}

A atividade de irrigação se dá principalmente nos vales, em terras de várzea e margeando os cursos d'água. Na área, cultiva-se: alface, abacate, banana, batata-doce, beterraba, cana-de-açúcar, cebola, cebolinha, cenoura, chuchu, coentro, cravo, feijão, flor-celsa, laranja-cravo, macaxeira, mamão, maracujá, milho e pimentão.

A irrigação se dá por aspersão (no caso das hortaliças e flores) e por sulco (no caso de chuchu, de frutíferas e de raízes), sendo que nas estiagens prolongadas o chuchu continua sendo irrigado, através de mangueiras. No período crítico de estiagem, quando a vazão já é naturalmente baixa e a acumulação nos reservatórios reduzida, os riachos e pequenos açudes utilizados para captação simplesmente secam, implicando em duas conseqüências perversas: a primeira é que é interrompido o suprimento de água para os açudes de abastecimento público, agudizando a situação de colapso na oferta de água para consumo humano; a segunda é que os cultivos ficam sem água, gerando redução de produtividade na safra e até mesmo, como ocorreu no período 1998/99, a dizimação de alguns plantios.

Utilizando-se estimativa de demanda evaporativa da cidade de Caruaru a partir de avaliações indiretas de valores diários para cada mês (Molle \& Cadier, 1992) e se assumindo uma eficiência de irrigação de $50 \%$, pode-se indicar valores máximos e mínimos de demandas hídricas para um período de quinze dias, de algumas das culturas cultivadas no Parque. As demandas máxima e mínima estão relacionadas à fase do desenvolvimento das culturas. Para efeito de ilustração, foram consideradas as estimativas de demanda hídrica das culturas para os meses tipicamente mais secos do ano, nos quais o suprimento de água para as culturas se dê forçosamente pela prática da irrigação (Tabela 4).

As estimativas constituíram apenas uma base inicial para a análise do uso consuntivo dos recursos hídricos, considerando-se a prática da agricultura no Parque Vasconcelos Sobrinho. Essas estimativas tendem a ser refinadas, uma vez especificados dados locais de climatologia, calendário das culturas (época de plantio), método de irrigação empregado e associado rendimento aproximado, e áreas de cada cultivo. Com base na oferta mensal de água através dos dados de precipitação e das diferentes demandas da água, incluindo-se a parcela utilizada para cultivo, pode-se determinar o balanço hídrico da área, elemento fundamental para o estabelecimento de diretrizes para o manejo do Parque.

\section{Conseqüências do desmatamento para a conservação dos mananciais}

Apesar do razoável estado de conservação da mata como um todo, verifica-se que em suas bordas, particularmente nas áreas de interface com a atividade agrícola, ocorre gradativo processo de desmatamento, com a substituição da floresta pelo cultivo, inclusive em vertentes de morro, implicando em aumento do escoamento superficial das águas de chuva e das águas de irrigação, aumento do albedo e da evapotranspiração, além da redução da infiltração, responsável pela recarga das águas subsuperficiais e pelo provimento dos mananciais de superfície, através das emergências do lençol freático.

Diante do exposto, torna-se mais do que evidente a necessidade de uma estratégia de conservação do Parque Vasconcelos Sobrinho, iniciando-se pelo reconhecimento de que a prioridade é a proteção dos recursos naturais (incluindose a floresta e a água).

Assim, é urgente um Plano de Manejo para a Unidade de Conservação e, a partir dele, uma gestão ambiental que priorize a conservação, reoriente os usos dos recursos naturais, desenvolva ações de recuperação ambiental e sensibilize a sociedade para a sua defesa, garantindo assim a sustentabilidade da área, enquanto Parque Ecológico.

\section{CONCLUSÕES}

A pesquisa realizada no período de dois anos no Parque Ecológico Vasconcelos Sobrinho, situado em Brejo dos Cavalos, permite apresentar as seguintes conclusões, em relação aos recursos hídricos e seus usos:

1. Na área estudada, a precipitação pluviométrica é superior à do seu entorno, numa proporção duas a quatro vezes maior.

2. O desmatamento progressivo da floresta, para cultivo agrícola, tende a alterar as condições microclimáticas locais, pois a mata funciona como uma "esponja biológica", em que a água precipitada é liberada gradualmente por evapotranspiração e por infiltração no solo.

3. O cultivo do chuchu é o principal consumidor de água (aproximadamente $44 \mathrm{~m}^{3} \mathrm{ha}^{-1} \mathrm{~d}^{-1}$ ) no Parque Vasconcelos Sobrinho, em evidente contradição com sua condição de Unidade de Conservação.

4. Os cursos d'água locais perdem vazão e até secam nos períodos em que coincide a estiagem com a intensa demanda para irrigação. 
5. O rápido escoamento superficial nas áreas desmatadas e a grande demanda de água para irrigação também acarretam secamento dos charcos, que acolhem normalmente a flora hidrófila e a fauna típica de ecossistemas úmidos ou alagados, buscando esses locais para dessedentação, alimentação e procriação.

6. Em contraponto ao comprometimento da vazão, a qualidade da água ainda permanece em patamares aceitáveis, para os parâmetros analisados.

\section{AGRADECIMENTOS}

Os autores agradecem ao PROBIO (MMA/BIRD/FADE) e ao CNPq.

\section{LITERATURA CITADA}

Andrade, G.O.; Lins, R.C. Introdução ao Estudo dos Brejos Pernambucanos. Arquivos do Instituto de Ciências da Terra, Recife, II 1964. p.21-34.

APHA - American Public Health Association. Standard methods for the examination of water and wastewater, 19 ed. Washington. 1995. 953p.

Braga, R.A.P. A Água e a Mata Atlântica. Seminário Nacional da Reserva da Biosfera da Mata Atlântica, 8, Ilhéus, Anais, 1999, Ilhéus: Conselho Nacional da Reserva da Biosfera da Mata Atlântica. 1999. p.1-10.

CETESB - Companhia de Tecnologia e Saneamento Ambiental. Guia de coleta e preservação de amostras de água. São Paulo, 1988. 150p.
Conservation International; Sociedade Nordestina de Ecologia; Biodiversitas. Mapa de áreas prioritárias para a conservação da Mata Atlântica do Nordeste. Recife, 1993.

CPRH - Companhia Pernambucana de Controle da Poluição Ambiental e de Administração dos Recursos Hídricos. Diagnóstico para recuperação do Parque Ecológico João Vasconcelos Sobrinho. Recife: CPRH, 1994. 29p.

Lima, D.A. Estudos fitogeográficos de Pernambuco. Arquivo do Instituto de Pesquisas Agronômicas, Recife, 1960. p.305341.

Molle, F.; Cadier, E. Manual do Pequeno Açude. Recife: SUDENE, 1992.511p.

Oliveira, C.A.S.; Carrijo, O.A.; Silva, W.L.C. Irrigação de algumas olerícolas: abóbora, abobrinha, alho, batata, cenoura, chuchu, ervilha, morango, pimentão e tomate. Brasília: EMBRAPA-UEPAE, 1980.36p.

Rodal, M.J.N. Florestas serranas de Pernambuco: Localização e conservação dos remanescentes de brejos de altitude. Recife: Imprensa Universitária, UFPE, 1998. 25p.

SECTMA - Secretaria de Ciência, Tecnologia e Meio Ambiente. Plano Estadual de Recursos Hídricos - Pernambuco. Recife: SECTMA, 1998.223p.

SUDEMA - Superintendência de Administração do Meio Ambiente. Paraíba: Perfil ambiental e estratégico da Paraíba. João Pessoa: SUDEMA, 1992. 170p.

Vasconcelos Sobrinho, J. As regiões naturais do Nordeste, o meio e a civilização. Recife: CONDEPE, 1971.441p. 